\title{
Review
}

\section{Politics and time}

Michael J. Shapiro (ed)

Polity Press, 2016, 208pp., ISBN: 978-1-5095-0780-1

Contemporary Political Theory (2018) 17, S13-S15. https://doi.org/10.1057/s41296017-0099-x; published online 7 March 2017

Politics and Time contributes to the bourgeoning literature on the politics of time and the event. Whilst the subject of "time" can be traced through a history of ideas, Michael Shapiro's contribution is unique in bringing together a number of political philosophers to consider how different conceptions of time inform and challenge the stories we are told about political events. The book draws on a range of political theorists, including Michel Foucault, Gilles Deleuze, Walter Benjamin and Paul Ricoeur. From the fluid time of biological rhythms to the choreographed time of industrial work, Shapiro presents a range of different temporalities that are experienced, negotiated, narrated and, at times, disrupted, through our understanding of the "event."

The book is organised into chapters based on a number of catastrophic events in U.S. history, including the U.S. bombing of Hiroshima, the devastation of Hurricane Katrina, the time-discipline of industrial work, and the atrocities of U.S. drone warfare. Whilst such events are varied in both their context and duration, Shapiro brings them together under the concept of "the sublime," which, drawing from Kant, offers a conceptual framework through which to understand how the "local (small) world connects with the hard-to-conceive larger world" (p. 121). The sublime here is defined here as the "stunning revelation" of this relationship between "the small, local world" and the "larger, interconnected world" that emerges through narrations of the event. (p. 161) For example, in the case of Hurricane Katrina, the disaster revealed that impoverishment, inequality, violence and racism were (and are) still present in, and part of, American society. Each chapter explores the politics and temporalization of the event with reference to the concept of the sublime; from "the nuclear sublime" in the case of Hiroshima, to the "racial sublime" in the case of Hurricane Katrina, "the sweatshop sublime" in examining industrial work and "the weapons sublime" of drone warfare. In doing this, Shapiro then provides a compelling argument that we must (continue to) pay attention to the "sublime" and the subjects whose lives make up the fabric of these events.

In each chapter, Shapiro also draws on a range of artistic and media genres - from documentaries such as Silva Kolbowski's After Hiroshima Mon Amour to Channel 4's Homeland TV series - to illustrate how counter narratives can work to disrupt official discourses of the event and its place in history. He argues that critically oriented films

(c) 2017 Macmillan Publishers Ltd. 1470-8914 Contemporary Political Theory Vol. 17, S1, S13-S15 www.palgrave.com/journals 
and documentaries can "provide challenges in the form of counter narratives and counter-visions to what Foucault famously calls the 'truth weapons' of governments which try to quarantine events within official interpretations, sedimented within (among other places) national museums and archives" (p. xiii). Through their editing capacities, documentaries and film have the potential to rewrite the political story and "repartition the senses of the world that official framings of historical time have shaped" (p. 21). He also demonstrates how advances in technology, such as the development of handheld video recorders and smartphones, have helped transform events from the local to the international (p. 87). The book includes a number of still-shots of the documentaries and films discussed, to help support his analysis of these materials. The materials cited are contemporary, engaging and relevant. They draw on a number of artistic and cultural texts that could be easily accessed or viewed by the reader.

Whilst a number of theories and ideas around the politics of time emerge throughout the book, at the heart of the Politics of Time is the notion that these artistic and cultural materials have disruptive potential in offering alternative temporal frameworks through which to view and, subsequently, understand the event. Shapiro (p. xi) considers, in-depth, "the relationships between official modes of problematization that emerge as "history" verses the lived temporalities of human assemblages" as well as "the contention between the biographic scripts lent to persons by official agencies ... and counter-biographies summoned in fictional and documentary texts." In doing so, he is making a key distinction between the time of an event that is felt and experienced on a personal level and time as understood through official narratives that place the event within history.

One example of the distinction between these conflicting temporalities can be found in the second chapter titled "Hiroshima Temporalities." The chapter starts by contrasting two media representations of the Hiroshima atomic bombing. Firstly, Shapiro discusses the film, titled Lost Sex, which follows the story of the "Master" who endures physical and mental trauma in the loss of his potency as legacy of the atomic bomb. The film ends with a camera shot of the character "watching the snowfall at his mountain residence" as a "lonely, unloved man" (p. 33). Shapiro then compares this to a simulated bombing run, broadcast on a local Hawaiian television station to mark the August 6th anniversary of the Hiroshima bombing. After the smoke bomb was dropped, the commentator declared it was "the bomb that ended the war" to which the audience stood up and cheered. The narration of these two events in "Hiroshima Temporalities" is used to illustrate how the temporal framing alters our understanding of the event; it changes its duration, its ending, and whose time is privileged in its (re)telling. The first representation of Hiroshima is situated in the biological time of the "Master" in which the event endures through the limitation imposed on his body and through individual memory. This contrasts to the second representation of Hiroshima which situates the event of Hiroshima in an historical time for which the event both starts and ends, and is remembered as past. 
It is this contrast between the time of history (and the state) and the time of lived experiences of the event that is carried throughout the book and used to illustrate what is politically at stake in our representation of the event. However, the difference between "official modes of problematization that emerge as "history" and "the lived temporalities of human assemblages" could have been explored with greater attention to what constitutes "lived temporalities of human assemblages" (p. xi). Shapiro makes reference to the time(s) of illness, sex, trauma, memory, routine, dance, movement and emotion. Arguably, all these constitute aspects of "lived experience" but this then opens up the possibility that historical time is also an element of (as opposed to just being disrupted by) "lived temporalities." Without defining what is meant by "lived temporalities" it is difficult to see to what extent it is separate from the temporalities that are presented to us through "biographic scripts" written by "official agencies" (p. xi).

The argument that "lived temporalities" are inherently disruptive is therefore less convincing than the argument for the potential of critically-orientated art and cinema/documentary to unsettle the official time of the historical event. As Shapiro argues, an analysis of competing temporalities is crucial to understanding the politics around what it means to read and write about the event. However, the book approaches such investigation through the medium of alternative and artistic representations of the event as opposed to (perhaps, the less well-defined) lived experience of the event. Editing techniques enable "time" in film to be easily manipulated, whereas this capacity to manipulate "time" perhaps does not always exist in the same way in the many aspects of "lived temporality" discussed above. To pursue what lived experiences of time means (for politics) would arguably require further engagement with the subjects who, as Shapiro acknowledges, are often written out of the story. It would require greater attention to what he calls the "micro-politics" of the event unmediated by cinematic techniques and artistic practices that aim to unsettle and disrupt (p. 40).

This is a methodological problem that Shapiro himself raises and discusses in the book. For example, the book ends with an afterword, reflecting on "an important part of [the] analysis" that is "the role of documentary genres in resurrecting and reinflicting the events" (p. 161). In this, Shapiro raises an important ethical debate about the extent to which victims of violent and catastrophic events can or should be (re)presented as part of the event through different modalities. These concluding remarks make Politics and Time a springboard for future discussions about the potential of different artistic and media genres to adequately reflect the multiple temporalities that constitute everyday experiences of the event.

Bethany Cuffe-Fuller

University of Exeter, Exeter EX4 4SB, UK byc201@exeter.ac.uk 